\title{
THREE CASES OF NIEMANN PICK'S DISEASE IN CHILDREN
}

\author{
BY \\ W. I. FORSYTHE, E. F. MCKEOWN and D. W. NEILL \\ From the Departments of Pathology and Child Health, The Queen's University, Belfast
}

(RECEIVED FOR PUBLICATION MARCH 23, 1959)

The classical description of Niemann Pick's disease is a disorder of lipoid metabolism, which is believed to occur almost invariably in infancy and to prove fatal within the first two years of life. The following three cases are recorded as unusual examples of the disease in patients, still alive, aged 19,9 and 10 years respectively.

\section{Clinical Summaries}

Case 1. A girl, aged 19 years, was seen at the age of 3, when her spleen was found to be enormously enlarged and her liver palpable four fingerbreadths below the costal margin. The heart and lungs were normal, and the superficial lymph nodes were not enlarged. There was no abnormal skin pigmentation. A moderate anaemia and leucopenia were present. The platelet count was normal and a bone marrow biopsy did not reveal any abnormal cells. At the age of 7 years a radiograph of the chest showed miliary mottling throughout the lung fields. Repeated tuberculin skin tests were negative. During the next 11 years this miliary appearance was replaced by a coarser mottling and reticulation of most of the lung fields (Fig. 1). At the age of 10 the patient was only $4 \mathrm{ft} .2 \mathrm{in}$. in height. The spleen was larger and extended to the brim of the pelvis. The blood picture was normal. No abnormal cells were found in bone marrow biopsy, but splenic puncture performed by Dr. M. G. Nelson revealed many large cells $20-30 \mu$ in diameter, with a small eccentric nucleus and abundant foamy cytoplasm. These had all the characteristics of Niemann Pick cells.

The patient was examined at intervals and by the age of 14 bone marrow biopsy showed many Niemann Pick cells. Liver function tests were repeatedly within normal limits, there was no radiological evidence of bone involvement and an electrocardiogram was normal. Apart from these findings the patient remained very well and had no respiratory or other complaints. At the age of 17 , however, she noticed a greatly increased sense of weight in her abdomen and was now conscious of her abdominal swelling which was causing her a certain amount of social embarrassment. Clinical examination showed a marked splenomegaly. She had an epistaxis, and blood examination showed W.B.C. count of $4,900 / \mathrm{c} . \mathrm{mm}$. and platelets $72,000 / \mathrm{c} . \mathrm{mm}$. These findings suggested a hypersplenic effect on the blood with thrombocytopenia and a tendency to bleeding. Splenectomy was advised and carried out on May 3. 1957. Following operation the W.B.C. count rose to $13,500 / \mathrm{c} . \mathrm{mm}$. and platelets to $258,000 / \mathrm{c} . \mathrm{mm}$. At the last follow-up examination on December 8, 1958, the patient was in good health with $\mathrm{Hb} 94 \%$ W.B.C. $17,700 / \mathrm{c} . \mathrm{mm}$. and platelets $264,000 / \mathrm{c} . \mathrm{mm}$.

FAmily History. Her father, mother and two sisters are alive and well, and have no splenic enlargement. There is no history of Jewish ancestry.

Case 2. This patient, now aged 9 years 2 months, was first seen at the age of 4 , when she had a sudden attack of abdominal pain, which persisted for 24 hours. Her mother felt her abdomen and found a lump as big as a grapefruit on the left side of her tummy'.

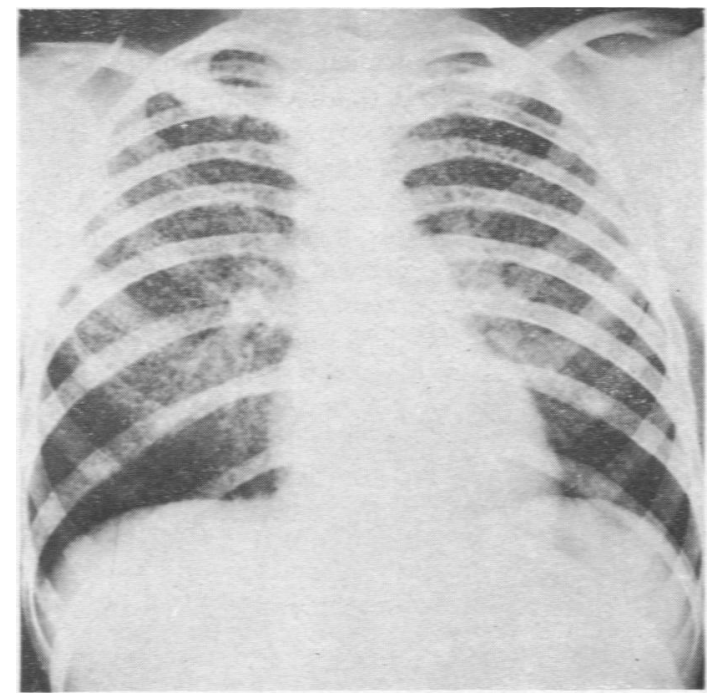

Fig. 1.-Case 1. Chest radiograph showing heavy mottling and reticulation of lung fields. 
Physical examination revealed an enlarged spleen, with the lower pole extending to the umbilicus, and the liver edge was palpable two fingerbreadths below the costal margin. Skin pigmentation was absent, and radiographs of the long bones were normal. A radiograph of the chest showed a soft mottling symmetrically distributed in both lung fields (Fig. 2). A bone marrow biopsy revealed large cells up to $40 \mu$ in size, with finely vacuolated cytoplasm and small nuclei, suggesting a diagnosis of Niemann Pick's disease (Fig. 3).

By the age of 7 a peripheral pancytopenia was noted, bone marrow biopsy showed a hyperplastic picture, and the spleen had increased considerably in size. Splenectomy was therefore advised and carried out on July 11, 1956. At the last follow-up examination on December 2, 1958 , the patient, then aged 9 years, had a $\mathrm{Hb}$ of $95 \%$, W.B.C. $10,700 /$ c.mm. and platelets $438,000 /$ c.mm., and felt perfectly well, although a radiograph of the chest at this time showed considerably increased mottling.

FAMILY History. The mother and father and their five other children were examined and subjected to bone marrow biopsy. No sign of Niemann Pick's disease was found except in an older sister (Case 3). There is no history of Jewish ancestry.

Case 3. This patient, a girl now aged 10 years 3 months, is a sister of Case 2. She was admitted to hospita1 at the same time, at the age of 5 , and was found to have an enlarged spleen palpable three fingerbreadths below the left costal margin, and the liver edge palpable two fingerbreadths below the right costal margin. The peripheral blood picture was normal and remained so during the next three years. Bone marrow biopsy showed numerous Niemann Pick cells. A radiograph of the chest revealed a fine diffuse mottling in both lung fields. Frequent examinations showed no other abnormal physical signs and at the last follow-up on December 2, 1958, the child was in good health with $\mathrm{Hb} 80 \%$,W:B.C. $4,800 / \mathrm{c} . \mathrm{mm}$. and platelets $106,000 / \mathrm{c} . \mathrm{mm}$. There are as yet no definite indications for splenectomy although the platelet count has fallen.

Pathology of Splenectomy Specimens. The spleen in Case 1 weighed $1,080 \mathrm{~g}$. and in Case 2, $875 \mathrm{~g}$. The pathological findings in both were identical and need not be described separately. Macroscopically the capsule was tense, and on section the pulp was firm and salmon pink in colour (Fig. 4). The Malpighian bodies and other structural markings were indistinct. Histologically the pulp was packed with large cells $20-40 \mu$ in diameter (Fig. 5). A few appeared to lie within the sinusoids, and not infrequently some occupied the centre of the Malpighian bodies. The cells had abundant foamy cytoplasm and rather small eccentric nuclei. A few were binucleated. They stained a delicate pink with $H$. and E., bright red with Scharlach R, pale blue with Mallory's aniline blue and blue-black with Smith Dietrich (Fig. 6).

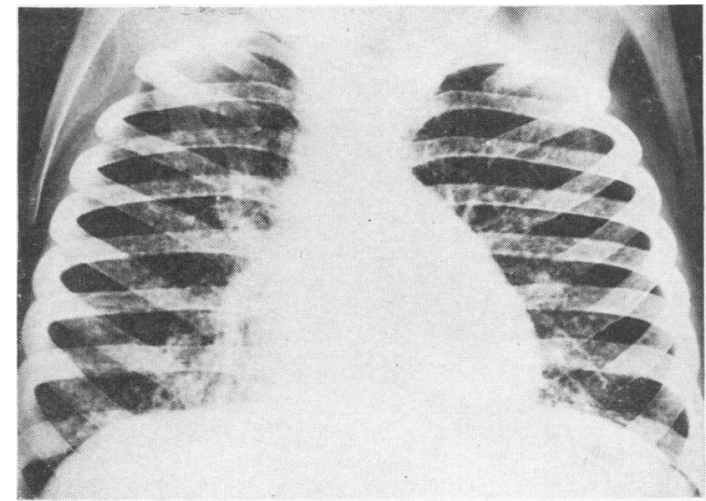

FIG. 2.-Case 2. Chest radiograph with coarse mottling of both lungs.

Phospholipid estimations were carried out on formalin-fixed material.

Method. Fixed spleen in $10 \mathrm{~g}$. portions was homogenized for 10 minutes in $50 \mathrm{ml} .0 .9 \%$ sodium chloride, using a domestic type of homogenizer, and $5 \mathrm{ml}$. portions of the homogenate were added drop by drop to $50 \mathrm{ml}$. alcohol-ether mixture $(5: 1)$, which was then brought to the boil in a water bottle, made to $100 \mathrm{ml}$. and filtered. The filtrate (representing $0.05 \mathrm{~g}$. spleen) was carefully evaporated to dryness in $5 \mathrm{ml}$. aliquots in tubes marked at $6 \mathrm{ml} ., 0.5 \mathrm{ml} .60 \%$ perchloric acid was added, and digestion allowed to proceed until colourless. After cooling, the contents of the tubes were diluted with $5 \mathrm{ml}$. water, when $0.4 \mathrm{ml} .5 \%$ ammonium molybdate and $0.2 \mathrm{ml} .1 \%$ ascorbic acid were added and mixed. The colours of the contents of the tubes were measured absorptiometrically at $700 \mathrm{~m} . \mu$ against that produced in a standard $0.02 \mathrm{mg}$. phosphorus solution similarly treated. The results are shown in Table 1.

TABLE 1

PHOSPHOLIPID ESTIMATION

\begin{tabular}{|c|c|c|}
\hline Spleen & Thannhauser (mg./100 g.) & Present Series (mg.) \\
\hline $\begin{array}{ll}\text { Normal } & \ldots \\
\text { Gaucher } & \ldots \\
\text { Niemann } & \text { Pick }\end{array}$ & $\begin{array}{l}5 \cdot 5-11 \\
9 \cdot 4 \\
42 \cdot 5\end{array}$ & $\begin{array}{ll} & 19 \cdot 5 \\
& \begin{array}{l}13 \cdot 8 \\
\text { Case 1: }\end{array} \\
\text { Case 28 } & 54\end{array}$ \\
\hline
\end{tabular}

From these findings it is evident that there is a greatly elevated phospholipid concentration in both spleens.

\section{Comment}

The occurrence of Niemann Pick's disease outside the period of infancy is exceptional, and for that reason the present cases are of some interest. According to Thannhauser (1950), only four verified cases in adults had been reported. Two of these were described by Dusendschon (1872) who confirmed the diagnosis by chemical analysis of the 


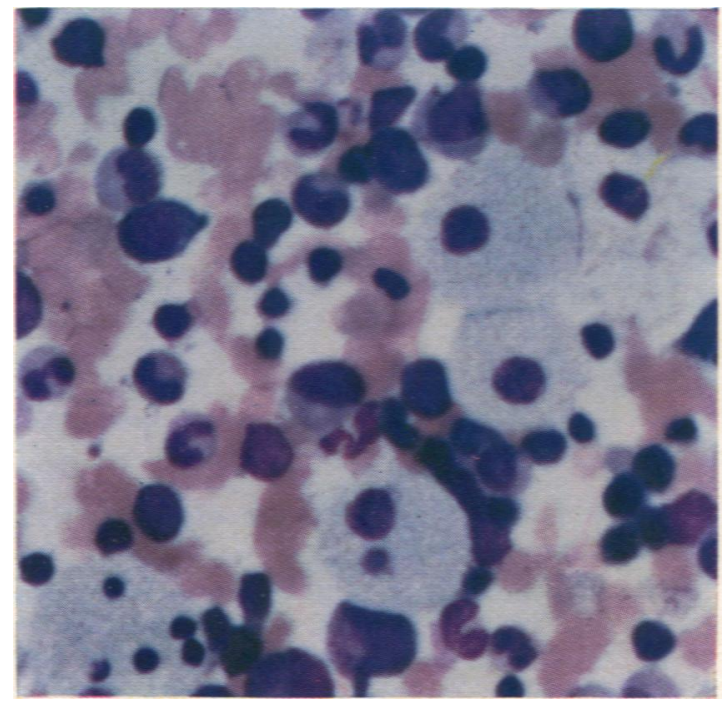

Fki. 3. - Case 2. Bone marrow smear showing several Niemann Pick cells with abundant foamy cytoplasm. (Leishman $\times$ 650.)

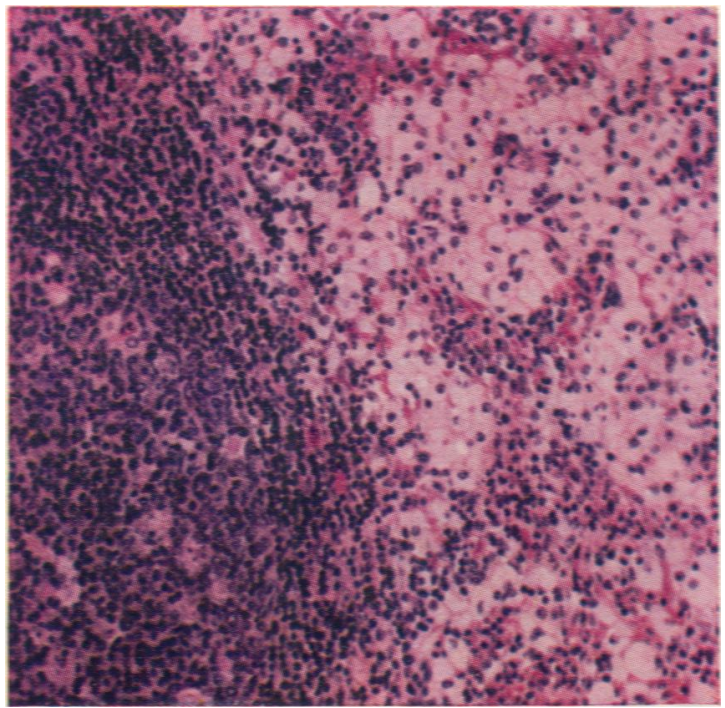

Fig. 5.-Spleen, with accumulation of Niemann Pick cells in the pulp. (H. and E. $\times$ 250.)

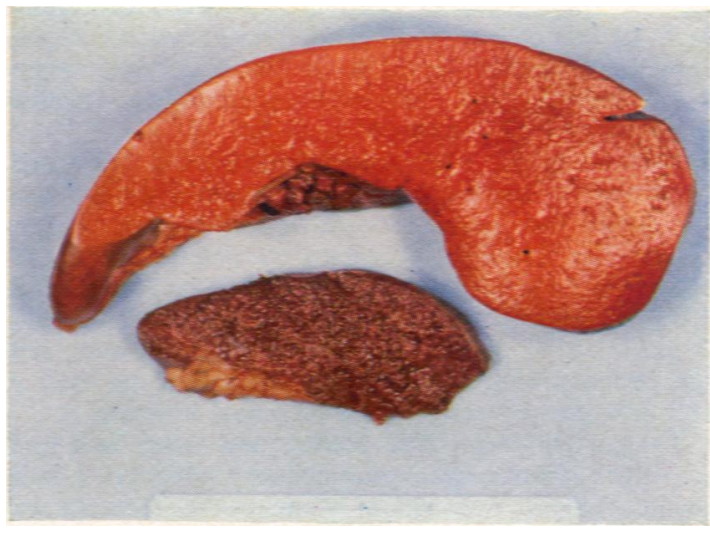

FiG. 4.- Splenectomy specimen with normal control showing great enlargement, and salmon pink coloration of cut surface.

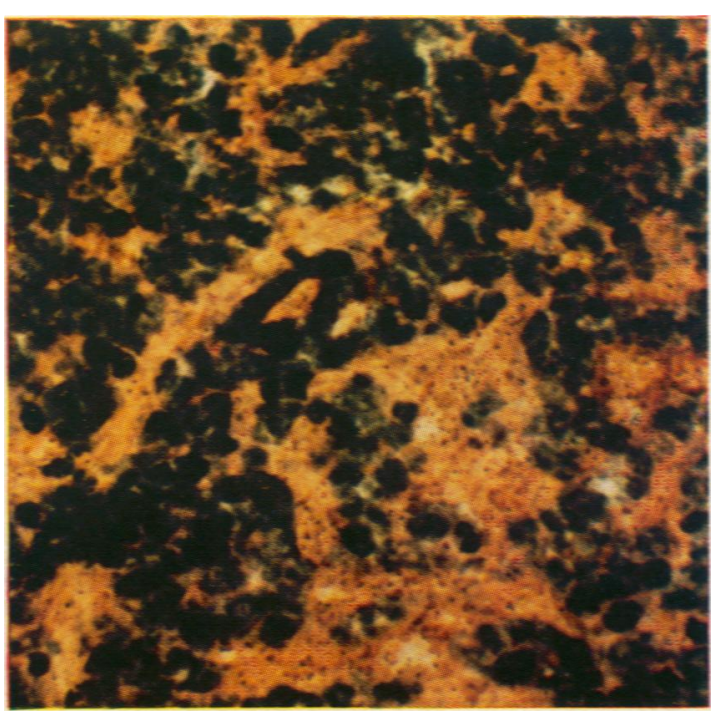

Fig. 6. - Spleen, showing Niemann Pick cells staining blue-black due to presence of phospholipids. (Smith Dietrich $\times 350$.) 
organs in two brothers aged 29 and 33 . Glanzmann (1943) reported the third case in an 8-year-old girl, and Farber and Thannhauser (1950) the fourth in an 8-year-old boy. In 1954, Terry, Sperry and Brodoff published a possible further case of adult lipoidosis of Niemann Pick type developing in a man of 52. Histologically the infiltrations in lungs, liver and spleen showed cells which resembled Niemann Pick cells in structure and staining characters, but chemical analysis of the affected tissues, though revealing increased amounts of phosphosphingosides, showed levels which did not come within the range generally found in infantile cases.

However, a recent review by Crocker and Farber (1958) presents data from 18 cases, five of whom died between the age of 3-6 years, three between $12-20$ years and one patient was still alive at 18 years, with the diagnosis made at 4 months of age. These writers emphasize the importance of recognizing that Niemann Pick's disease has a broader range of biological behaviour than is usually stated, and that it may not have an invariably rapid and fatal course with death in early infancy. They suggest that if the early critical phase of the disease can be survived a non-progressive state may be entered with long survival.

The occurrence of these adolescent and adult types of the disease tends to allow of a correlation with the other diseases of lipoid metabolism. Thus Gaucher's disease may present as an infantile, adolescent or adult type. Letterer-Siwe's disease is also recognized in infancy and adult life, whilst the cerebral lipoidosis described by Tay Sachs may also present in infancy or adolescence.

The clinical diagnosis in the present three cases rested on the finding of the characteristic large foam cells in the bone marrow and in the spleen. These cells, varying in size from $20-40 \mu$, stained lightly acidophilic with H. and E., pale blue with Mallory's aniline blue, to some extent bright red with Scharlach $R$ and heavily blue-black with Smith Dietrich. The latter stain is specific for phospholipids. Since the disease is a disturbance of lipid metabolism in which large quantities of phospholipids, and in particular the diaminophosphatide, sphingomyelin, accumulate within the affected organs, the final diagnosis depends on demonstrating by chemical analysis a significant increase in the amount of sphingomyelin present. In both splenectomy specimens a very high content of phospholipid was found, far above normal, and even above the range generally recorded in most cases of Niemann Pick's disease. It is worth noting that the weights of the spleen in these two cases greatly exceed that of any recorded case, the heaviest being $480 \mathrm{~g}$.
The value of splenectomy in this condition is doubtful. In some patients it has been carried out merely for relief of pressure symptoms. In others, as in two of the present cases, there may be a 'hypersplenic' blood picture, and splenectomy has led to improvement. According to Crocker and Farber (1958) at least there is no evidence that the procedure hastens the progression of the disease or subsequently lowers resistance to infection.

The prognosis in these non-infantile cases is uncertain. As a metabolic disorder the disease is likely to be chronically progressive. Nevertheless in spite of evidence of involvement of lungs, liver, spleen and bone marrow over a period of years in the three cases here recorded, each patient is in excellent health. Since a radiograph of the lungs shows a heavy miliary mottling and obviously denotes extensive infiltration with Niemann Pick cells, it is possible that increasing pulmonary fibrosis, which is usually associated with these infiltrations, may lead to right ventricular failure. This occurred in one of Dusendschon's cases (1872). The pulmonary lesions may also render the patients more liable to intercurrent infection. On the other hand, the hepatic infiltrations may later be associated with cirrhosis. This was described in both of Dusendschon's cases. However, his patients were alcoholics and it is doubtful which was the decisive factor, as cirrhosis has not been reported in the adult form of Gaucher's disease. With pulmonary, hepatic, splenic and bone marrow involvement in the three present cases it is difficult to envisage the disease being other than progressive.

\section{Summary}

Niemann Pick's disease is generally confined to early infancy, but its occurrence in three patients, still alive, aged 19, 9 and 10 years respectively, is described. In spite of evidence of pulmonary, hepatic, splenic and bone marrow involvement, the general health of the patients is good. It is possible that the form of Niemann Pick's disease in older subjects may run a chronic and relatively benign course.

We are indebted to Dr. R. Marshall and Dr. W. A. B. Campbell for permission to study Case 1 and Cases 2 and 3 respectively, to Mr. D. Mehaffey for the illustrations and to the Northern Ireland Hospitals Authority for a grant towards research work.

\section{Rerentances}

Crocker, A. C. and Farber, S. (1958). Medicine (Baltimore), 37, 1. Dusendschon, A. (1872). Thèse, Faculté de Médecine, Genève.

Farber, S. and Thannhauser, S. J. (1950). Unpublished. Cited by Thannhauser, S. J. (1950). Lipidoses, 2nd ed. p. 564.

Glanmman, E. (1943). Schweiz. med. Wsch., 73, 1414.

Terry, R. D., Sperry, W. M. and Brodofi, B. (1954). Amer. J. Path., 30, 263 .

Thannhauser, S. J. (1950). Lipidoses, 2nd ed. Oxford University Press, New Yort. 